\title{
Technology Enhanced Learning: Utilizing a Virtual Learning Environment to Facilitate Blended Learning
}

\author{
David Tucker and Laurie D Jones \\ Manchester Metropolitan University, \\ Manchester, United Kingdom
}

\author{
d.tucker@mmu.ac.uk; l.jones@mmu.ac.uk
}

\begin{abstract}
This paper describes how we at the Manchester Metropolitan University Business School. (MMUBS) have adopted a blended learning approach to teaching information and communication technology (ICT) skills to our first year undergraduate students. This innovative approach has enabled us to deliver a high quality educational experience whilst, at the same time, making more effective use of traditional teaching methods. We will describe the development of blended learning at MMUBS and we will provide evidence that our approach has secured a substantial, positive impact student on learning and at the same time improved cost effectiveness.
\end{abstract}

Keywords: blended learning, information technology, virtual learning environment

\section{Introduction}

At the Manchester Metropolitan University Business School (MMUBS) all first year undergraduate students are required to demonstrate competence in a range of Information and Communication Technology (ICT) skills including word processing, databases and spreadsheets. We are finding that UK students entering HE are generally competent in using features of a word processor, such as spellchecking and text formatting, but are less competent in using features such as automatically generating a table of contents. In contrast, some students come to us with a high level of ICT competence. Hence, it is important to develop a system of learning and teaching that addresses these widely differing levels of ability.

In the United Kingdom, the Qualifications and Curriculum Authority (QCA) have concluded that:

"Until recently, the terms basic skills or 'skills for life' were widely assumed to cover the skills of adult literacy and adult numeracy. In today's society however, information and

Material published as part of this publication, either on-line or in print, is copyrighted by the Informing Science Institute. Permission to make digital or paper copy of part or all of these works for personal or classroom use is granted without fee provided that the copies are not made or distributed for profit or commercial advantage AND that copies 1) bear this notice in full and 2) give the full citation on the first page. It is permissible to abstract these works so long as credit is given. To copy in all other cases or to republish or to post on a server or to redistribute to lists requires specific permission and payment of a fee. Contact 0HPublisher@InformingScience.org to request redistribution permission. communication technology

(ICT) can be just as important, particularly in the workplace." (QCA, 2006).

This statement suggests that acquisition and development of appropriate ICT skills will underpin our student's ability to prosper in an academic environment and beyond into their working life. 


\section{The Blended Learning Approach to Education}

In the academic year 2007/8, around 1350 undergraduate students were recruited onto first year degree programs. Dealing with such a large cohort brought about some significant challenges. The problem facing our academic staff was how to deliver a high quality learning experience whilst at the same time making effective and efficient use of finite resources.

Until 2006 learning, teaching and assessment of ICT skills were tutor-led sessions in computer laboratories. Students would spend one hour per week in a lab over a 10-week term. Each student was provided with a printed copy of a workbook. Students were expected to progress through the workbook and complete 15 practical tasks. At appropriate points, the workbook instructed the students to ask their laboratory tutor to assess their capability in each task. Because of the large amount of students, some undertook the unit in the autumn term and others in the spring term. Hence, if the second group of students had deficiencies in any areas of ICT skills it was at the end of the spring term before the teaching staff became aware of them.

The summative assessment was by means of a project that required students to bring together all 15 tasks to solve a substantial business problem. They were then required to demonstrate their project to a tutor. This in itself was a significant burden on the lab tutors. Each student had to demonstrate their knowledge of their project in a face-to-face situation. Twelve tutors were involved in the delivery of the unit many of whom worked on a part-time basis. This was a very time consuming process and the student's learning experience was being compromised because the tutors were spending significantly more time in signing off tasks than they were in helping students to understand key concepts. The labs that were held towards the end of each term were becoming frantic affairs. Almost every student was demanding 10-15 minutes of a tutor's time either to sign off tasks or to ask questions. Clearly, this was not in the student's best interest. It was felt that adopting a blended learning approach would offer a way of dealing with these challenges. MMUBS had already experienced a successful implementation of one form of blended learning through the delivery of the Info Skills unit (Donnelly, Jones, \& Matthews, 2006).

There are many definitions of blended learning. For example Kovaleski states that blended learning "combines traditional classroom sessions with e-learning and self-study" (2004 , p. 17), whilst Bershin offers "blended learning programs use many different forms of e-learning, perhaps complemented with instructor-led training and other live formats" (1994, p. 23). At MMUBS, blended learning is regard as the use of traditional teaching methods complimented and enhanced by an e-learning component. The e-learning component can be asynchronous (such as a self-paced on-line course) or synchronous course (such as an instructor led on-line course). The challenge of blended learning is to use the most economical mix of available resources to achieve the desired outcomes.

Before the process of creating a blended learning approach for IT skills started, the benefits that it was hoped the students would gain were defined. These were:

- Assess the ability of each student in ICT skills as early as possible in the academic year to identify weaknesses and address them.

- Expect to improve student retention.

- Encourage students to become independent learners.

- Provide an impartial, summative assessment.

- Improve the effective and efficient use of traditional teaching resources.

- Improve the effective use of ICT resources within MMUBS. 
In the blended learning approach, a series of computer-based learning and teaching tools were developed. The student's paper-based workbooks were converted into "active workbooks", online workbooks which contained a series of self-test questions. Once a student had answered a question, they received instant feedback. Each student could assess their own progress, at their own pace and in their own time. With this innovation, the first step towards creating a flexible and dynamic mode of teaching had been taken. See Figure 1 for an example of the on-line workbook.

\section{Changing Traditional Approaches to Teaching ICT Skills}

Previously the ICT Skills unit was delivered in the computer labs. The largest lab contains 26 computers. To enable each student to have 10 hours of lab time consumed 510 staff hours. This high staff-student ratio was dictated to us for two reasons. Firstly, because staff had to spend considerable time signing off the student's tasks and projects, a staff-student ratio of more than 25:1 was infeasible. Secondly, the physical size of the computer labs restricted the number of students at any one time. The new method of delivery enabled an increase in this ratio without compromising the learning experience. However, the capacity of the labs was still a constraint. The unit was therefore restructured and delivered in block-mode that ran at the beginning of the autumn term. Instead of using the computer labs the computer drop-in centre, which contains $180 \mathrm{com}$ puters, was used. Each student had four two-hour supervised lab sessions. This contact time was supplemented by traditional lectures in which students were given guidance regarding the key IT Skills concepts. Thus, the student contact time was no less than in previous years.

The lab sessions were used not only to teach ICT skills but also to talk to students about their responsibilities at university and to try to instill in them the importance of becoming independent learners. With 175 students and 5 staff in each session, the staff-student ratio was increased from $25: 1$ to $35: 1$. In block-mode we were able to provide the same level of service to our students in 320 hours. Even adding on the 40 hours of staff time required to invigilate the summative assessment sessions this amounted to a considerable saving of staff time. An unexpected benefit of delivering the unit in block mode was that during the lab sessions the students began a socialization process. Students were grouped in the labs according to their respective programmes of study and it was found that they soon began to discuss the teaching material with each other and to help each other to understand key concepts. From this stemmed embryonic social relationships that helped the new students to feel more comfortable in their new environment and to identify with their respective programmes of study. Another benefit that was noticed was that the number of queries directed to the Information Systems Support team, such as how to change network passwords, was reduced significantly for the remainder of the academic year. 
4 Now that you have entered the Formula for YEAR 1 intoCell B5, then it can be copied to the other Years. Do this, so that your Spreadsheet takes the following form:

\begin{tabular}{|l|l|r|r|r|r|r|}
\hline & A & B & C & D & E & \multicolumn{1}{|l|}{} \\
\hline $\mathbf{1}$ & INTEREST $=$ & $\mathbf{1 0}$ & & & & \\
\hline $\mathbf{2}$ & & & & & & \\
\hline $\mathbf{3}$ & START VALUE & AFTER & AFTER & AFTER & AFTER & AFTER \\
\hline $\mathbf{4}$ & & YEAR 1 & YEAR 2 & YEAR 3 & YEAR 4 & YEAR 5 \\
\hline $\mathbf{5}$ & $\mathbf{1 0 0 . 0 0}$ & 110.00 & 121.00 & 133.10 & 146.41 & 161.05 \\
\hline
\end{tabular}

5 It is highly likely that your Spreadsheet does NOT take the above form.

We thus have a problem.

Let us try to determine why this is so.

6 Click on Cell B5.

From the Formulas tab, in the Formula Auditing group, click Trace Precedents.

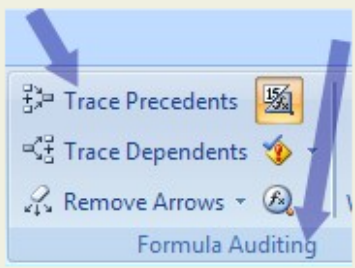

The Arrows show us that Cell B5 depends upon Cell B1 and Cell A5: this is correct.

7 In the Formula Auditing tab click on Remove Arrows.

8 Click on Cell C5.

From the Formula Auditing tab point at Trace Precedents.

9 We now see that the reference to B1, the Cell containing the INTEREST RATE, has become C1, because EXCEL has used a RELATIVE COPY!

\section{Figure 1. A sample from the on-line workbook}

To enable students to become accustomed to their e-learning environment a "Using your ELearning Environment" hyperlink on their homepages was created. This link contained an FAQ section which provided answers to questions which students had submitted to staff either by email or in person during the tutored lab sessions. The teaching staff soon realized that many students were asking the same questions. In response to this, a method of dynamically updating the teaching material we conceived. At the end of each two-hour lab session the tutors would discuss what questions had been asked and the unit leader then wrote a tutorial (in Microsoft Word) 
which would address the most widely asked questions. The tutorial was converted to a web page and added to the on-line teaching material. Typically this process took $1 \frac{1}{2}-2$ hours. The ability to update the on-line teaching material in such a dynamic manner has proved to be an invaluable part of the learning and teaching process.

Where a student's engagement with the unit was of major concern, an e-mail was sent to the relevant personal tutor or course leader. When students realized they were being monitored in this way it served as a motivator. A further motivator was that the on-line assessments contributed towards the student's final mark for the unit.

\section{On-Line Formative Assessments}

The next step in the blended learning approach was to create a series of on-line formative assessments to replace the 15 manual tasks. The questions in the formative assessments were multiple choice questions (MCQs) or short answer. It was important to design the questions so that they tested a student's understanding of the key concepts and not just that the "spreadsheet was right". Using Bloom's taxonomy (1956), the aim was to devise questions that would test student's ability to solve problems using required skills or knowledge. This was achieved by requiring students to complete certain tasks, such as creating a spreadsheet, before taking an assessment and then having to make changes to that spreadsheet during the assessment. The students would need to show that they understood the concepts if they were to obtain the correct answer. Hence, careful design of the questions was crucial. Sayers, Nicell, and Hagan (2004) point out that question design is often carried out without sufficient analysis of the nature of the questions or how they would create better learning opportunities. Guidance about writing suitable MCQs that would test application of knowledge was taken from McKenna and Bull (1999) and from colleagues at MMU who had spent many years researching MCQ design (Higgins \& Tatham, 2003).

Now that the formative assessments were computer-based and provided useful feedback, tutors had significantly more time to spend interacting with students. Hence, the computer labs became what they were supposed to be, an environment in which students could readily engage with the unit. Those students who were struggling with the key concepts, and who could demonstrate that they had made genuine attempts at the formative assessments, could discuss their issues with an experienced tutor. Students became accustomed to using the on-line material in their own time and coming to the labs with pre-prepared questions. The whole learning experience became a richer one for both staff and students. The students used the lab sessions to discuss the unit content with each other and hence these labs provided a forum that encouraged peer support and integration.

On completion of a formative assessment, students received relevant feedback instantly. If an answer was not the correct one then the student would receive feedback in the form: "It seems that you might not understand the concept of X, refer to Y". The feedback provided guidance as to why the answer might be incorrect but did not reveal the actual answer. Students would then be directed to an alternative resource which would provide additional guidance. The resource might be an external web site, the intranet or any other information source that offered a student the opportunity to understand the concept. Having had this opportunity the student could then take the formative assessment once more.

Students quickly became accustomed to the notion that lab tutors would only provide assistance if there was clear evidence of a genuine attempt to engage with the unit (Stubbs \& Martin, 2003). They were also aware that the access to the on-line material was recorded so that tutors could monitor each student's level of engagement with the teaching material. This encouraged students to develop independent-learning skills and to regard lab tutors as the last source of advice. 
At the end of the delivery of the unit, we undertook a survey of student opinion about the method of delivering the ICT skills unit. Over 500 responses were received. The survey clearly indicated that the great majority of students had a positive attitude towards this way of learning. The data showed that the feedback and guidance provided at the end of the formative assessment did help them to understand the key concepts.

The qualitative feedback proved useful in identifying ways to improve the delivery of the unit. Also the feedback provided a useful mechanism for students to provide their comments on the design of the teaching material. Based on this feedback the teaching material was redesigned to better meet the student's needs. For example, material was grouped logically into various content modules and a 'Welcome' guide was included to answer questions about the rationale for studying the unit.

\section{On-Line Summative Assessments}

Delivering formative assessment electronically was a very new experience for the tutors. The teaching staff reflected on the positives and negative of this approach and, taking careful note of the student feedback, decided that the same approach would be taken with the summative assessment. In other words the summative assessment would be delivered and marked via our virtual learning environment (VLE). This had the immediate benefit of freeing lab tutors from the timeconsuming task of face-to-face assessment of the project. In the traditional mode of delivery student often complained that some tutors were stricter in marking the tasks than others. The on-line assessment was perceived as more equitable and very few complaints were received from students about their grades. Assessments were time constrained and invigilated. Sufficient question alternates were devised so as to minimize the possibility of a student attempting to gain an unfair advantage. The randomization features of our VLE were utilized fully to further increase the variety of questions. An example of a question is shown in Figure 2. Student's who missed a summative assessment, or who obtained a poor mark, were contacted by e-mail informing them that they needed to attend remedial lab sessions. From the data that was stored automatically in the database the specific skill areas that the students were finding difficult to grasp were easily identified. Of 274 students who were reassess 211 were successful. This was a significant increase compared with previous years. 


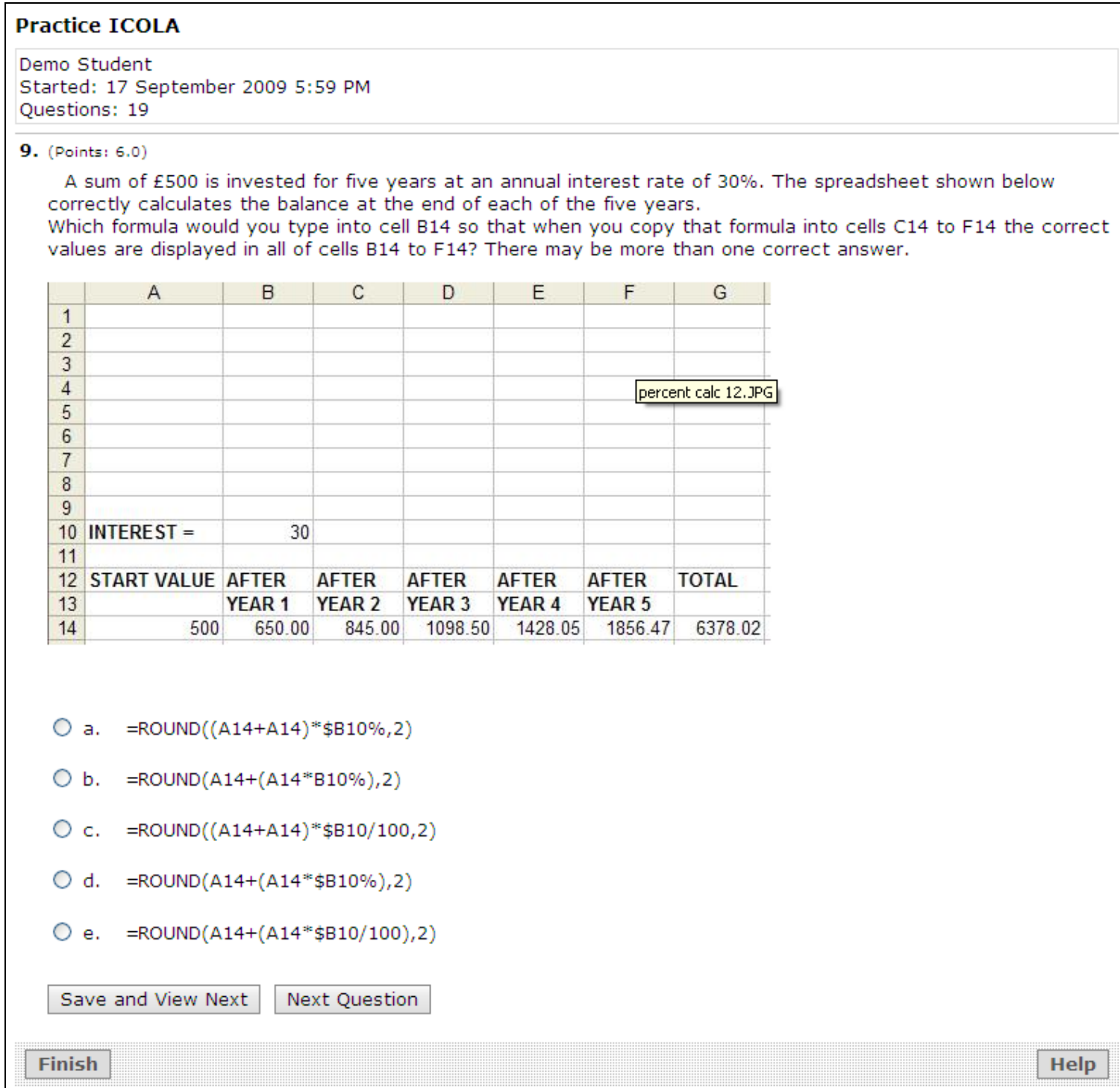

Figure 2. One question from the on-line assessment

\section{Reflection}

In dealing with 175 students at the same time in the computer drop-in centre, a major disadvantage was found that it was difficult to convey key concepts to students via the 'chalk and talk' method. In the traditional mode of delivery we had a maximum of 26 students in a computer lab. It was a simple matter for a tutor to gather four or five students around a whiteboard and to go though a key concept. In the drop-in centre the logistics of this were much more difficult to organize and the teaching team felt that some degree of personal contact between student and tutor had been lost. However because these were first year undergraduate students in their first two weeks at university they had no reason to feel that this way of delivery was anything but the norm. For the staff this process did highlight a need to vary the staff/ student ratios in the labs. In the early sessions there were few questions relating to the teaching material. This was because the first lab sessions were used mainly to introduce students to the university, the ICT skills unit and to solve any technical problems accessing the university systems. Questions related to the teaching material began to arise in the second lab sessions and became more intense during the third 
and fourth ones. Hence it was realized that the fewer staff were needed in the earlier sessions and more in the latter sessions.

A different factor then became worth considering and that was whether academic staff members were needed in all labs. Now that the teaching had been separated from the assessment, the using teaching assistants in the labs could be considered.

Another factor that had not been envisaged was that of how to maintain a professional culture in computer labs beyond these first two weeks of the first term. By the end of the first term, reports had been received from staff that student's behavior had deteriorated. In hindsight, measures should have taken to inform colleagues that we would expect them to reinforce the behavior patterns that had been instilled in them in their first two weeks at university. Tangible measures to address this issue are being taken and these involve staff awareness sessions and the development of podcasts showing what happens during these early weeks.

These innovative changes to the ICT skills unit have proved to be popular with both students and staff. Figures 3 to 5 present data taken from the end-of-unit survey which was completed by over 500 students just after they had completed the unit. The data indicates very clearly that the students regarded their experience as a very positive one.

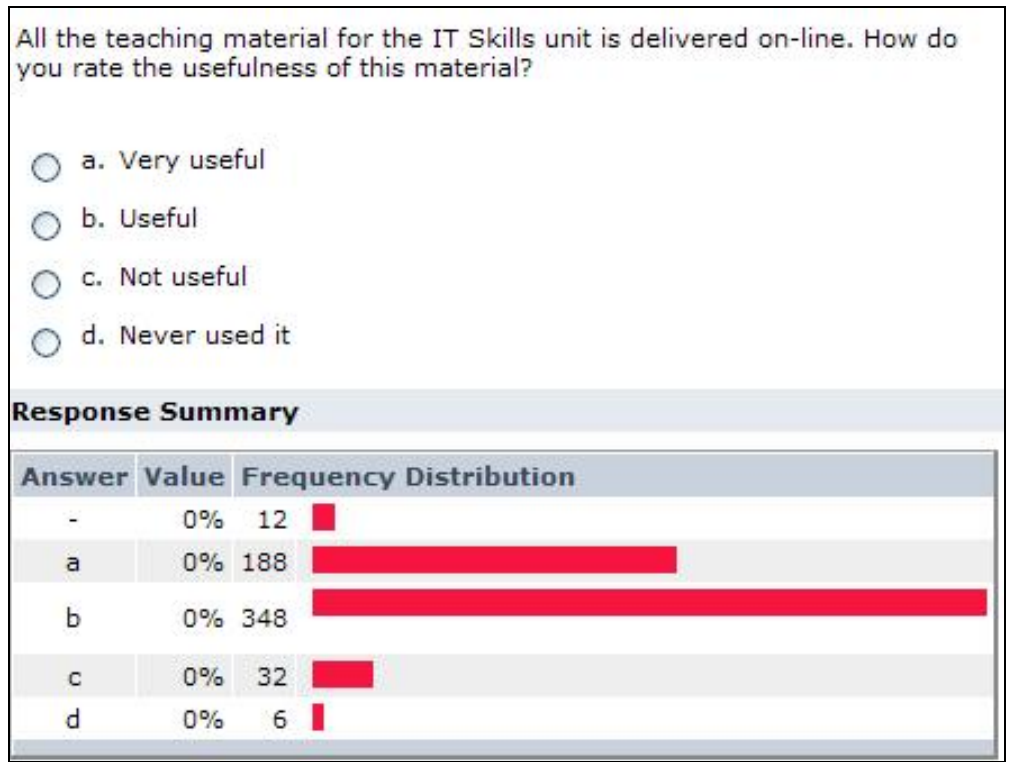

Figure 3. Usefulness of the material 


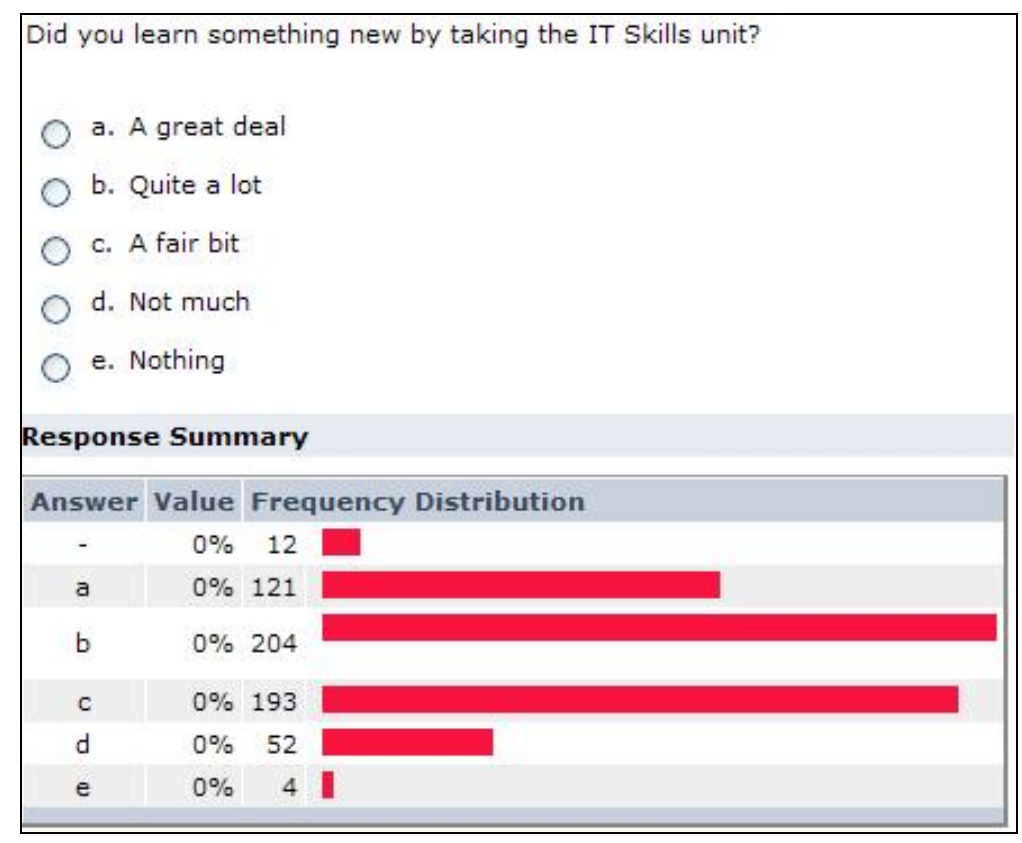

Figure 4. Level of learning

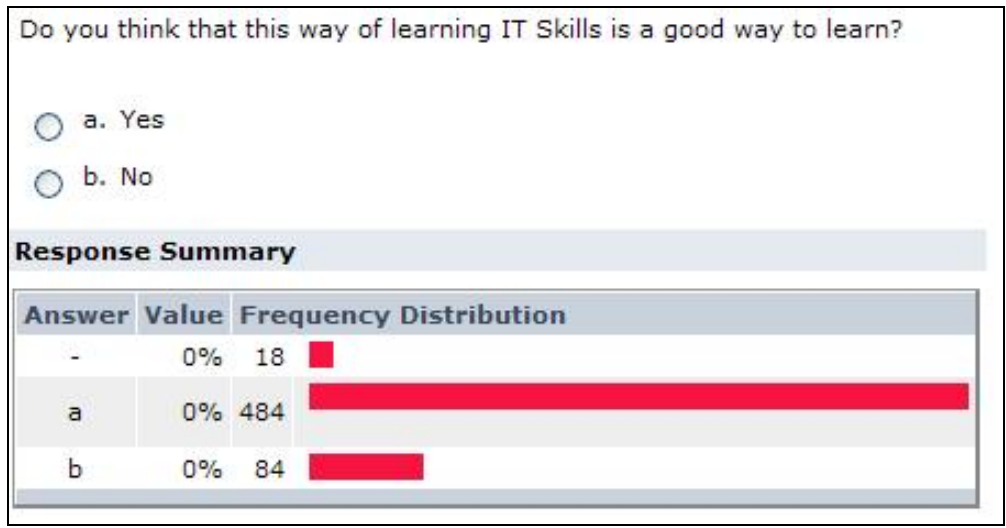

Figure 5. Method of learning

Students have been able to acquire rapidly the basic ICT skills which they need to complete assignment work in other units of study. It is hoped that this will have a positive effect on the quality of their work and will improve student retention levels. Another advantage of this approach is that at the end of the two weeks we had collected extensive data which indicated any general areas of weakness. With this information we developed remedial teaching material to address these weaknesses, concentrating resources where they would have maximum impact.

The benefits that we have accrued so far:

- students encouraged to become independent learners

- students worked at their own pace and mostly off-campus

- improved discipline of students

- for the remainder of the academic year, students had to concentrate on five core units of study rather than six

- students immediately began a socialization process with peers 
- students with weaknesses in ICT skills were identified much earlier in the academic year so that remedial action could be taken quickly and thus impact positively on student performance

- on-line material updated dynamically so as to address quickly the needs of students

- reduction in the amount of staff hours consumed by the unit

- computer labs freed up for most of the academic year which goes some way to addressing student concerns about access to ICT resources

- able to dynamically customize on-line teaching material

- student monitoring much improved leading to greater student attention

- induction week became a more important experience for students and staff

- routine queries to our Information Systems team (e.g. how to change network passwords) greatly reduced

- students became aware of the full range of on-line learning resources offered by MMU.

- instilled a professional culture into the students

\section{The Future}

Many other unit leaders at MMUBS now wish to incorporate some element of blended learning into their teaching portfolio. They have seen the tangible benefits that have accrued in the ICT skills unit and wish to provide their students with the same benefits. It is hoped that by incorporating more blended learning the future will bring about more benefits to MMUBS and its students. The exciting challenge is to ensure that this blended learning approach continues to provide a "splendid learning" opportunity for the students.

The ICT Skills innovation has attracted considerable interest from other academic institutions. We wish to share our experiences with other institutions that wish to explore this approach. One of the authors has been invited to deliver talks about the project at a number of institutions and would be delighted to do so in the future.

\section{References}

Bershin, J. (1994). The blended book of learning. San Francisco: Pfeiffer.

Bloom, B. S. (1956). Taxonomy of educational objectives: The classification of educational goals. Handbook I, Cognitive domain. New York: Longmans Green,

Donnelly, K., Jones, R. \& Matthews, D. (2008). Blended learning in action: The InfoSkills Programme at Manchester Metropolitan University's Library Service. Proceedings of the Learning and Teaching conference: Blended Learning to Splendid Learning, Manchester Metropolitan University Business School, 34-42.

McKenna, C., \& Bull, J. (1999). Designing effective objective questions: An introductory workshop. Retrieved from http://caacentre.lboro.ac.uk/dldocs/otghdout.pdf

Higgins, E., \& Tatham, L. (2003). Exploring the potential of multiple-choice questions in assessment, Learning and Teaching in Action, 2(1). Retrieved from http://www.ltu.mmu.ac.uk/ltia/issue4/higginstatham.shtml

Kovaleski, D. (2004). Blended learning in focus. Corporate Meetings \& Incentives, 23, 35-36.

Qualifications and Curriculum Authority. (2006). Basic skills. Retrieved from http://www.qca.org.uk/596.html

Sayers, H. M., Nicell, M. A., \& Hagan S. J. (2004). Supporting and assessing first year programming: The use of WebCT. Innovation in Teaching and Learning in Information and Computer Sciences, 3(1). Retreived from http://www.ics.ltsn.ac.uk/pub/italics/Vol3-1/sayers/Italics.htm 
Stubbs, M., \& Martin I. (2003). Blended learning: One small step, Learning and Teaching in Action, 2(3). Retrieved from http://www.ltu.mmu.ac.uk/ltia/issue6/stubbsmartin.shtml

\section{Biographies}

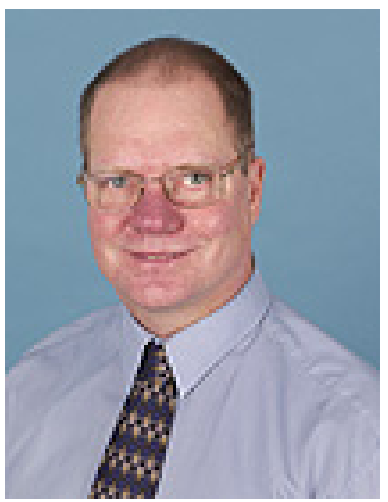

David Tucker is a senior lecturer at Manchester Metropolitan University Business School. He spent many years researching into the use of ICT in a variety of environments including manufacturing companies and SMEs before concentrating his research in the area of learning and teaching. For more details visit his MMU web page at:

http://www.business.mmu.ac.uk/staff/staffdetails.php?uref=124

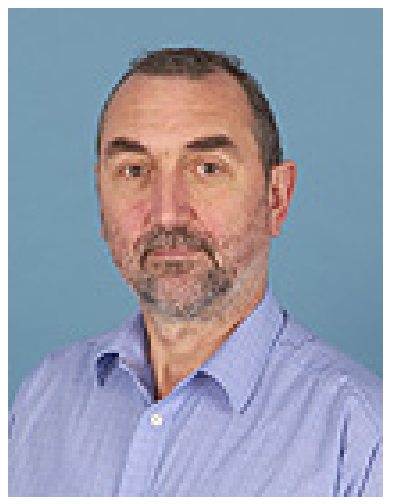

Laurie D. Jones is a senior lecturer at Manchester Metropolitan University Business School. Having spent 20 years working in ICT in industry, mainly for Small and medium sized enterprises, he joined MMU in 1996. Since then he has spent most of his research time into the use of ICT in SMEs. In particular, how they use the Internet for marketing and e-commerce. For more details visit his MMU web page at: http://www.business.mmu.ac.uk/staff/staffdetails.php?uref $=115$ 